Article

\title{
Development of a Ventilation System Using Window Cavity
}

\author{
Jinuk Lee ${ }^{1} \mathbb{D}$, Sanghoon Park ${ }^{2}\left(\mathbb{D}\right.$ and Taeyeon Kim ${ }^{1, *}$ \\ 1 Department of Architectural Engineering, Yonsei University, 50 Yonsei-ro, Seodaemun-gu, \\ Seoul 03722, Korea; rumor7@nate.com \\ 2 Division of Architecture, College of Engineering, Sun Moon University, Sunmoon-ro 221 beon-gil, \\ Tangjeong-myeon, Asan-si, Chungnam 31460, Korea; sanghoon@sunmoon.ac.kr \\ * Correspondence: tkim@yonsei.ac.kr
}

Received: 7 September 2020; Accepted: 9 October 2020; Published: 12 October 2020

\begin{abstract}
A household unit of an existing apartment in which residents lived was selected, and the indoor air quality in each space of the unit was measured for analysis. Analysis of the measurement data indicated that the concentration of carbon dioxide $\left(\mathrm{CO}_{2}\right)$ constantly increased beyond $1000 \mathrm{ppm}$ when a resident stayed indoors for an hour or more. Specifically, the concentration of $\mathrm{CO}_{2}$ increased when the resident was asleep to a level wherein negative impacts on health were observed. Moreover, the inflow of particulate matter (PM) was mainly caused by natural ventilation from the outside rather than the behavior of indoor residents, which generated an insignificant amount of PM. This study proposes a new ventilation system for solving the above-described problems. According to the system, when a window is closed, the window cavity created between a new frame and the existing frame is utilized as an air path for ventilation. The application of this system ensures a stable amount of ventilation through forced ventilation and prevents the inflow of external PM. Moreover, this system was designed to recover indoor heat through the window cavity and facilitate the pre-heating of outdoor air through heat collection based on solar radiation during the day.
\end{abstract}

Keywords: existing apartment buildings; indoor air quality; carbon dioxide $\left(\mathrm{CO}_{2}\right)$; particulate matter (PM); ventilation system; window frame

\section{Introduction}

There has been an increasing interest in the indoor air quality of buildings, as it is closely related to the health of residents. The indoor air quality of houses is affected mainly by pollutants that flow through ventilation and infiltration from the outside as well as those generated indoors. Pollutants generated from indoor building materials and furniture tend to decrease over time [1], and the levels of such pollutants are also being reduced through the current application of environmentally-friendly materials and mandatory measurement of air quality in newly constructed apartment buildings. However, pollutants generated by residents must be continuously managed. The main pollutants include $\mathrm{PM}, \mathrm{CO}_{2}$ generated from breathing, carbon monoxide (CO), and nitrogen oxides (NOx) generated from cooking.

Previous studies have indicated that the concentrations of $\mathrm{CO}_{2}$ and $\mathrm{PM}$ (i.e., $\mathrm{PM}_{10}$ and $\mathrm{PM}_{2.5} ; \mathrm{PM}_{10}$ is particulate matter 10 micrometers or less in diameter, $\mathrm{PM}_{2.5}$ is particulate matter 2.5 micrometers or less in diameter) in houses in Korea tend to exceed both the Korean and international standards for indoor air quality, and that maintenance regarding such pollutants is required. Special attention is needed to examine indoor air quality during the sleep time of a resident, which accounts for one-third of the day [2-6]. Bekö et al. [7] noted that the ventilation rate was likely to be low during the sleep time of residents. Canha et al. [8] also reported that the concentration of pollutants increased during 
the sleep time of residents. Many studies have been conducted to analyze the relationship between the concentration of pollutants during sleep and the quality of sleep. Some studies found that the work efficiency of residents the next day increased when the concentration of $\mathrm{CO}_{2}$ in their sleeping areas decreased [9-12]. Other studies [13] were also conducted to examine the relationship between the level of indoor exposure of residents to PM and the quality of their sleep. As a result, the hypnagogic state of residents during sleep time and their symptoms such as headaches and sore throats after sleep improved when they were less exposed to PM than usual. The results of the aforementioned studies show the importance of ventilation in that the degree of exposure to PM has a significant impact on the human body. Currently, three types of ventilation systems are being applied in residential buildings. The first is a ceiling-type ventilation system. Because the installation of a ventilation system became mandatory in 2006 in a residential area that was permitted for construction and included 100 households or more, ceiling-type ventilation systems, among the mechanical ventilation systems, have been generally applied. Other types of ventilation systems include natural ventilation systems and mechanical ventilation systems, both of which are installed on the envelopes of buildings.

Natural ventilation systems cannot ensure a stable amount of ventilation, because they rely on the difference in pressure between indoor and outdoor areas [14,15]. Moreover, these systems increase indoor cooling and heating loads, because outdoor air at high temperatures during the summer and low temperatures during the winter comes directly inside $[16,17]$. Some natural ventilation systems are equipped with filters as well as an existing method of window opening and closing, although they do not show a high level of efficiency for preventing PM [18-20]. Several studies have proposed natural ventilation systems that can recover heat through double glazing. Specifically, these systems were designed to recover heat lost from the inside to the outside and obtain heat through solar radiation during the daytime using the cavity of double glazing as an air path [21-26].

Ceiling-type ventilation systems account for most of the ventilation systems installed in houses. As wall perforation and ceiling construction are required to install ceiling-type ventilation systems, they are applied at once in all the units of buildings during new construction. In these systems, an amount of ventilation of 0.5 air changes per hour is set as a domestic standard for apartments and multi-use facilities. These systems can reduce the cost of air-conditioning and heating through heat recovery and ensure a stable amount of ventilation based on mechanical ventilation. However, they are unlikely to be installed in existing homes and cannot be moved to different places once they are installed. It is also difficult to perform maintenance work for the ducts and filters used in these systems. In addition, economic burdens regarding a great amount of construction costs are expected when they are installed in each household unit of the building [27].

Studies are being conducted to develop mechanical ventilation systems installed on the envelope of a building, which ensures convenient access to solve the aforementioned problems. There is a system that directly installs a ventilation device inside the outer wall, and there is a system that supplies fresh air into the inner space using the outer wall itself as a ventilation air path [28-32]. However, this type of mechanical ventilation system based on the use of the outer wall has disadvantages in that the wall structure must be replaced or perforation must be performed on the existing wall structure. In this regard, studies on mechanical ventilation systems using opening parts are also being performed [33]. This type of mechanical ventilation system can be easily installed in the existing windows in the horizontal or vertical form. Some mechanical ventilation systems using opening parts can also reduce energy consumption through heat exchange. However, when this type of mechanical ventilation system is installed as a separate unit to the opening part, it can lead to problems such as a requirement for a large area, the disturbance of a hypnagogic state, and difficulty in providing an external view owing to the installation of a fan, a heat exchanger, and a flow path.

Accordingly, this study aims to develop a new ventilation system that is applicable to existing homes and can be easily installed by anyone. In summary, the developed system must secure sufficient ventilation, ensure pre-heating at cold temperatures in winter, and block particulate matter. 
Furthermore, the system should perfectly fit into the existing windows and occupy as small an area as possible such that the view from the inside cannot be obstructed.

To derive performance criteria and functions of a ventilation system, apartment households occupied by residents were selected first, and the indoor air quality encompassing $\mathrm{CO}_{2}$, indoor/outdoor PM levels, temperature, and humidity were measured in each space. Each of the target households was divided into a living room/kitchen, a master bedroom, and a second bedroom. Occupants use each space for different purposes. Occupants' behaviors (sleep, cook, rest, and so on) and air quality were analyzed for each space to derive implications. Based on these implications, the concept of a ventilation system necessary for improving air quality was designed. Then, an ultimate ventilation system was developed through a simulation-based optimal design considering the performance under both operating and non-operating conditions of the fan.

\section{Methods}

\subsection{Measurement of Indoor Air Quality}

\subsubsection{Outline}

Figure 1 shows the measurement target. The target apartment unit is located in Magok-dong, Gangseo-gu, Seoul-si. As the apartment building was constructed in April 2017, it is typically classified as a newly built apartment. In this apartment unit, the area for exclusive use was established as 84.98 $\mathrm{m}^{2}$, with the floor level as $2.3 \mathrm{~m}$, and the number of floors as 10. A central heating system was applied, and an air-conditioner installed in a living room for family use was not operated during the experiment.

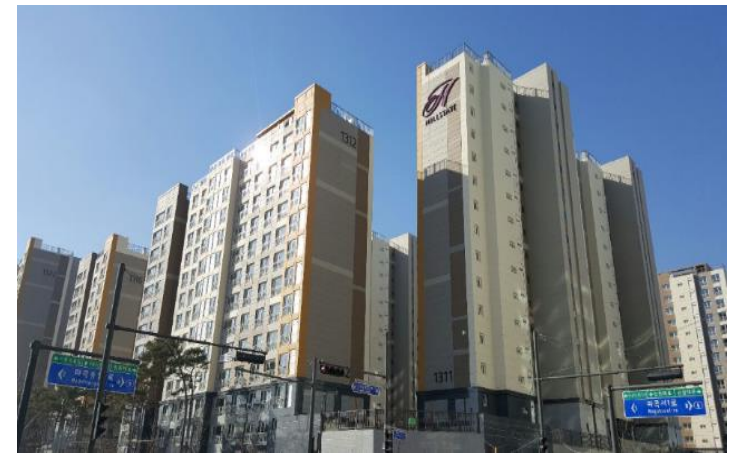

(a)

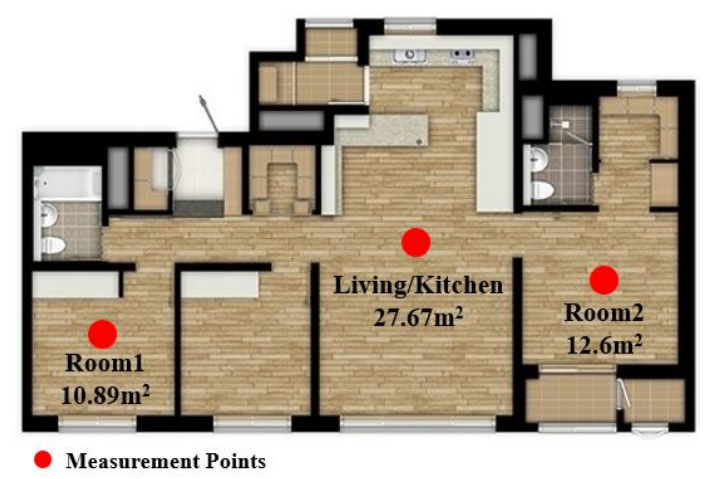

(b)

Figure 1. Measurement target. (a) The view of the apartment selected for measurement. (b) The floor plan and measurement points.

The living room and kitchen, Room 1 and Room 2, were selected as experimental target areas because residents used these areas for specific purposes, and their behavior was regular within them. The experimental period was selected as 30 September 2019 to 30 October 2019 to identify changes in indoor air quality caused by natural ventilation. Four people lived in the target household unit, including two working adults and two preschool children. Residents did not stay in the place during the daytime on weekdays in which adults went to workplaces and children went to a kindergarten. Therefore, the density in the unit was high in the morning and the evening. Measurements of indoor temperature and humidity (TESTO480), $\mathrm{CO}_{2}$ (TESTO480), and internal and external PM (AEROCET 531S) were performed to obtain data for the analysis. The measurement time was set differently based on the external weather conditions and the schedules of residents for staying in the unit. Because $\mathrm{CO}_{2}$ mainly came from residents' breathing, it was measured mainly at the time when the density of residents staying in the place was high. PM was mostly positively correlated with high outdoor PM levels $\left(\mathrm{PM}_{10}>50 \mu \mathrm{g} / \mathrm{m}^{3}, \mathrm{PM}_{2.5}>25 \mu \mathrm{g} / \mathrm{m}^{3}\right.$ according to WHO standards) and a high rate of indoor 
activities performed by the residents. The central points of each space were selected as measurement points, and the height was set as 1.2 to $1.5 \mathrm{~m}$ from the floor.

\subsubsection{Data Analysis}

Figure 2a shows the concentration of $\mathrm{CO}_{2}$ in the living/kitchen rooms. When two adults and two preschool children stayed in these rooms for an hour or more, the concentration of $\mathrm{CO}_{2}$ exceeded 1000 (domestic recommended standards for indoor air quality) ppm, which was the standard for the indoor air quality. Notably, the concentration of $\mathrm{CO}_{2}$ exceeded $1500 \mathrm{ppm}$ during the evening time when cooking was performed. However, it decreased to $1000 \mathrm{ppm}$ or less when natural ventilation was performed for $10 \mathrm{~min}$, and it was measured as 500 to $600 \mathrm{ppm}$ at midnight, during which time residents did not stay in these places owing to infiltration.

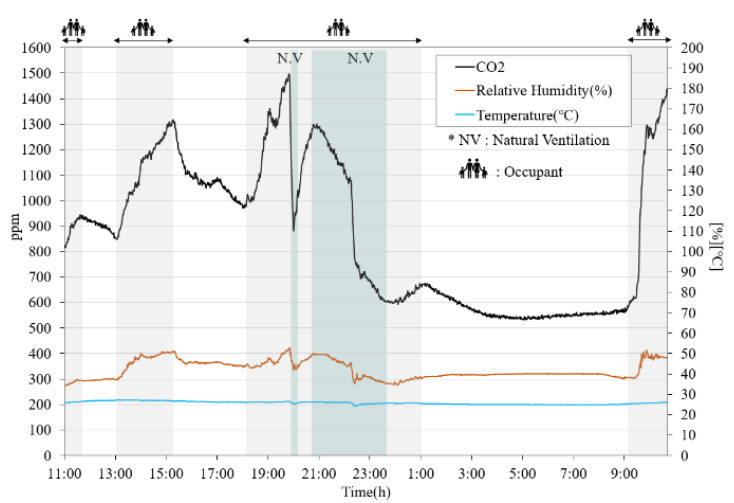

(a)

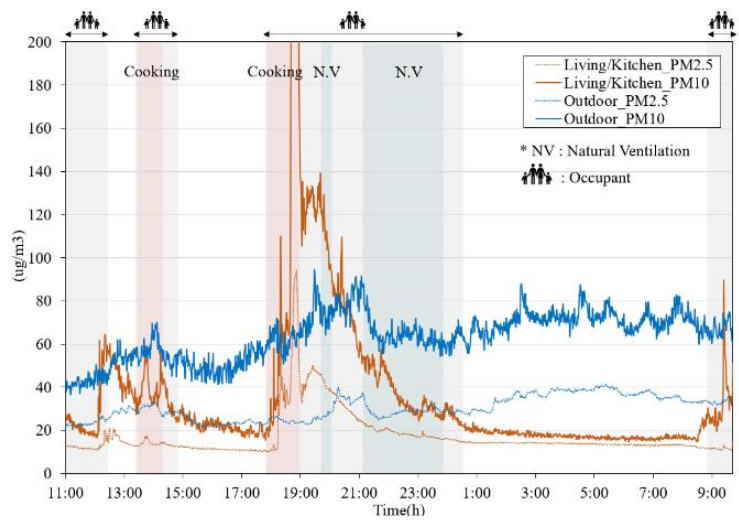

(b)

Figure 2. Carbon dioxide $\left(\mathrm{CO}_{2}\right) /$ particulate matter $(\mathrm{PM})$ concentration of the living/kitchen area. (a) $\mathrm{CO}_{2}$ concentration and (b) $\mathrm{PM}_{10}$ and $\mathrm{PM}_{2.5}$ concentrations.

Figure $2 \mathrm{~b}$ shows the concentration of $\mathrm{PM}$ in the living/kitchen areas. The outdoor concentrations of $\mathrm{PM}_{10}$ and $\mathrm{PM}_{2.5}$ during the experimental period were 40 to $90 \mu \mathrm{g} / \mathrm{m}^{3}$ and 20 to $40 \mu \mathrm{g} / \mathrm{m}^{3}$, respectively. Based on this result, the concentration of internal PM was affected by factors related to the behaviors of residents rather than external effects. Notably, the concentration of $\mathrm{PM}_{10}$ rapidly increased to 470 $\mu \mathrm{g} / \mathrm{m}^{3}$ during the cooking time.

Figure 3a shows the concentration of $\mathrm{CO}_{2}$ in Room 1. A resident used this room for taking a rest and sleeping after working. The concentration of $\mathrm{CO}_{2}$ in this room constantly increased after the resident came in and exceeded $2700 \mathrm{ppm}$ after the resident woke up in the morning. Subsequently, it decreased to $1000 \mathrm{pm}$ or less through natural ventilation for $10 \mathrm{~min}$. Based on this result, the supply of outdoor air through ventilation was required given that the target room was used for specific purposes, that the residents used the room regularly, and that the concentration of $\mathrm{CO}_{2}$ was notably high.

Figure $3 \mathrm{~b}$ shows the concentration of PM in Room 1. During the experiment, the outdoor concentration of $\mathrm{PM}_{10}$ was as high as $260 \mu \mathrm{g} / \mathrm{m}^{3}$ and that of $\mathrm{PM}_{2.5}$ ranged from 30 up to $120 \mu \mathrm{g} / \mathrm{m}^{3}$. The concentration of internal PM was maintained at an acceptable level without being greatly affected from the outside owing to the insignificant impact of infiltration. However, the concentration of internal PM tended to temporarily increase somewhat when the resident came in or out of the room owing to the resuspension of PM. When natural ventilation was performed, the concentration of $\mathrm{PM}_{10}$ instantly increased by approximately three to four times to $140 \mu \mathrm{g} / \mathrm{m}^{3}$.

Figure 4a indicates the concentration of $\mathrm{CO}_{2}$ in Room 2. An adult and two preschool children used this room for sleeping at night. The concentration of $\mathrm{CO}_{2}$ constantly increased to approximately $4000 \mathrm{ppm}$ after they began sleeping in the room. This result was derived because the output of $\mathrm{CO}_{2}$ was high based on the spatial volume, and the room was sealed for several hours. The concentration of 
$\mathrm{CO}_{2}$ decreased to $1000 \mathrm{ppm}$ or less through natural ventilation performed for $30 \mathrm{~min}$ after the target residents woke up.

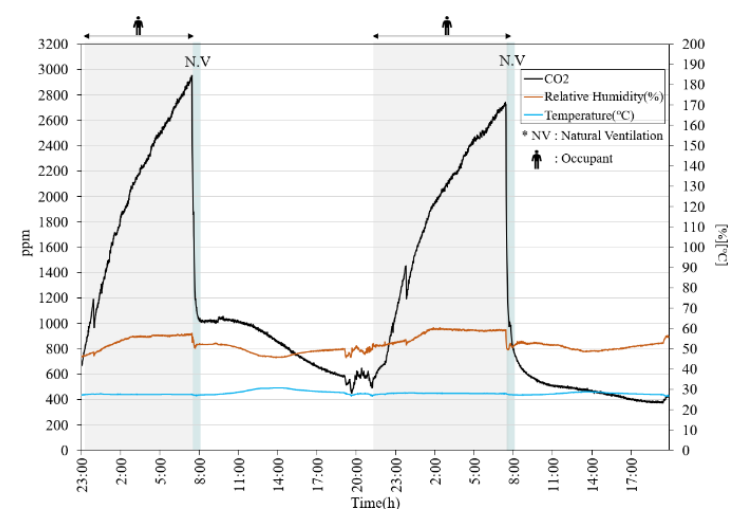

(a)

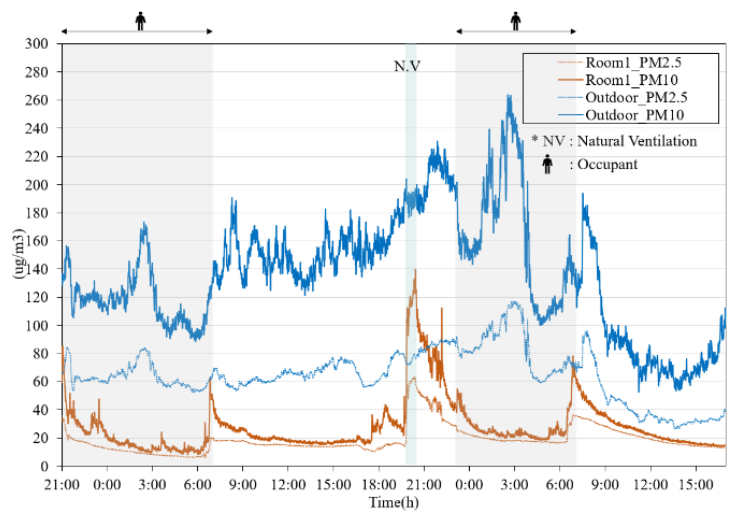

(b)

Figure 3. Carbon dioxide $\left(\mathrm{CO}_{2}\right) /$ particulate matter $(\mathrm{PM})$ concentration of Room 1. (a) $\mathrm{CO}_{2}$ concentration and (b) $\mathrm{PM}_{10}$ and $\mathrm{PM}_{2.5}$ concentrations.

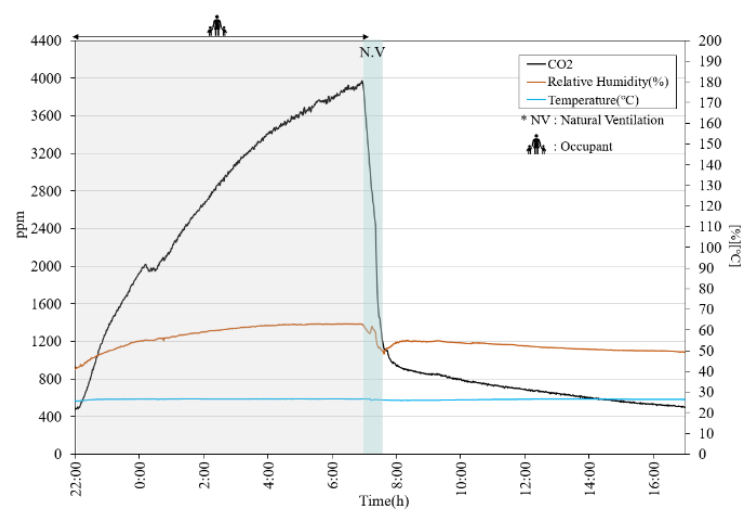

(a)

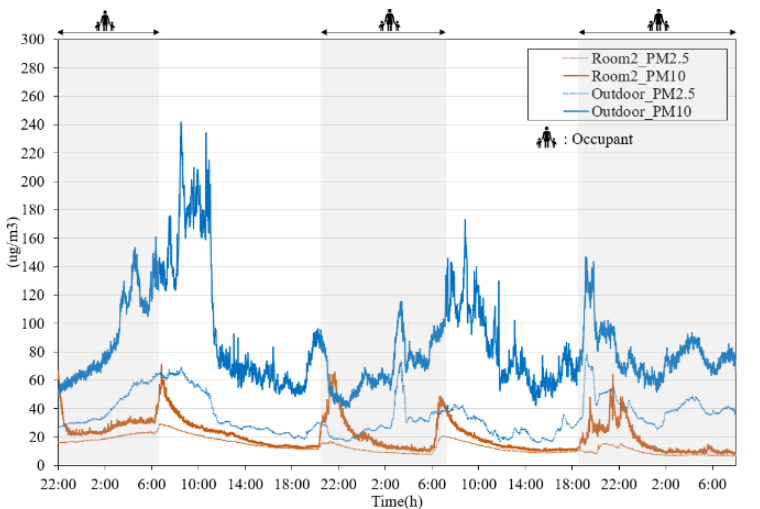

(b)

Figure 4. Carbon dioxide $\left(\mathrm{CO}_{2}\right) /$ particulate matter $(\mathrm{PM})$ concentration of Room 2. (a) $\mathrm{CO}_{2}$ concentration and (b) $\mathrm{PM}_{10}$ and $\mathrm{PM}_{2.5}$ concentrations.

Figure $4 \mathrm{~b}$ shows the concentration of PM in Room 2. During the experiment, the outdoor concentration of $\mathrm{PM}_{10}$ was as high as $50-240 \mu \mathrm{g} / \mathrm{m}^{3}$, and that of $\mathrm{PM}_{2.5}$ ranged from 20 up to $80 \mu \mathrm{g} / \mathrm{m}^{3}$. The concentration of internal PM was maintained at an acceptable level without being greatly affected from the outside owing to the insignificant impact of infiltration. However, the concentration of internal PM tended to temporarily increase somewhat when the residents came in or left owing to the resuspension of PM. External effects were insignificant because natural ventilation was not performed in this room.

\subsection{Development of Ventilation System}

\subsubsection{Concept Development}

A small room similar to Room 1 based on spaces composing the floor plan of a general apartment household unit was selected as the target area for the application of the ventilation system in this study. This room was selected given that a small room is used for specific purposes, such as working and sleeping, and that the improvement of air quality is required owing to the large amount of $\mathrm{CO}_{2}$ emissions compared to the spatial volume based on the aforementioned experimental results.

Figure 5 shows the concept of the ventilation system. An additional window frame with a ventilation function is applied to the existing window. Thus, when the window is closed, a cavity, 
which is created between window frames, serves as an air path for ventilation. The additional frame has the same material and finishing as the existing frame, thereby ensuring design consistency. On the outside, the frame does not show any application of the mechanical system. Another advantage of the proposed system is that, as the width is $65 \mathrm{~mm}$, it occupies as small an area as possible and minimally affects the view from the inside.

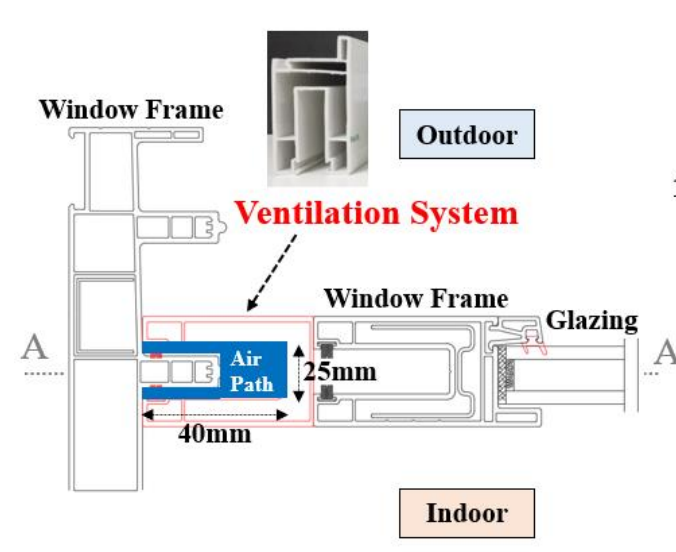

(a)

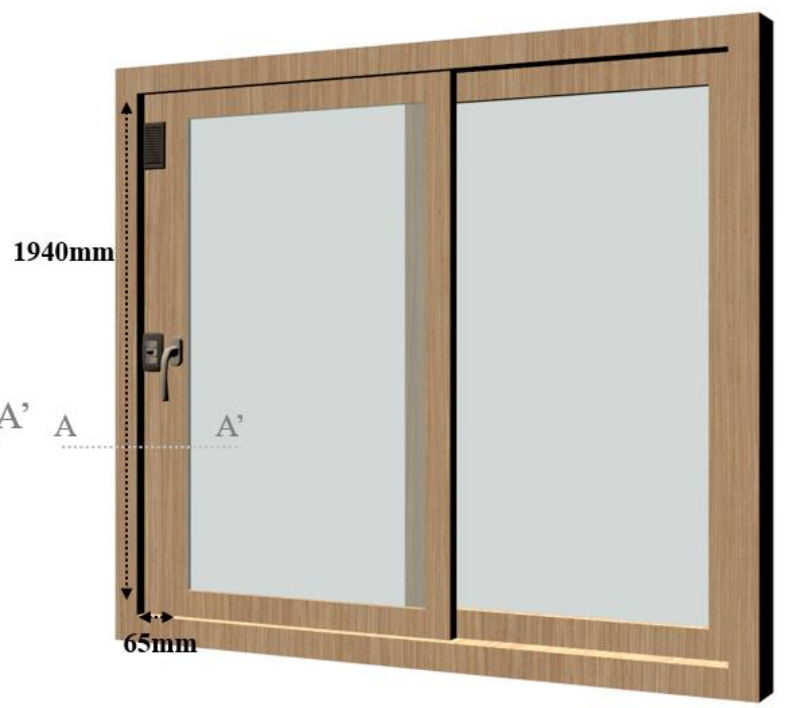

(b)

Figure 5. Ventilation system concept. (a) Drawing and (b) installation of ventilation system.

Polyvinyl chloride (PVC), a generally used material for windows, is used for the ventilation system, and this system is formed in a "U"-shape consistent with the existing window frame. This system can be attached or detached on the existing window frame and does not generate either a gap or a distance in the process of installation for airtightness. The cavity is $45 \mathrm{~mm}$ in width, $20 \mathrm{~mm}$ in depth, and $1940 \mathrm{~mm}$ in height and serves as an air path connected to the outdoor air intake and the indoor air supply outlet.

Figure 6 shows the operational principle of the ventilation system under the condition of winter temperatures. When heating is performed to set the indoor temperature to 20 to $24{ }^{\circ} \mathrm{C}$, indoor heat is transferred to the cavity based on convection and conduction. In other words, the air at a temperature of 0 to $5{ }^{\circ} \mathrm{C}$, which flowed from the outside, was supplied to the indoor areas through pre-heating to reduce energy consumption and ensure the thermal comfort of residents. During the daytime, the effects of solar radiation led to an increase in the internal temperature of the cavity and acquisition of additional heat. 

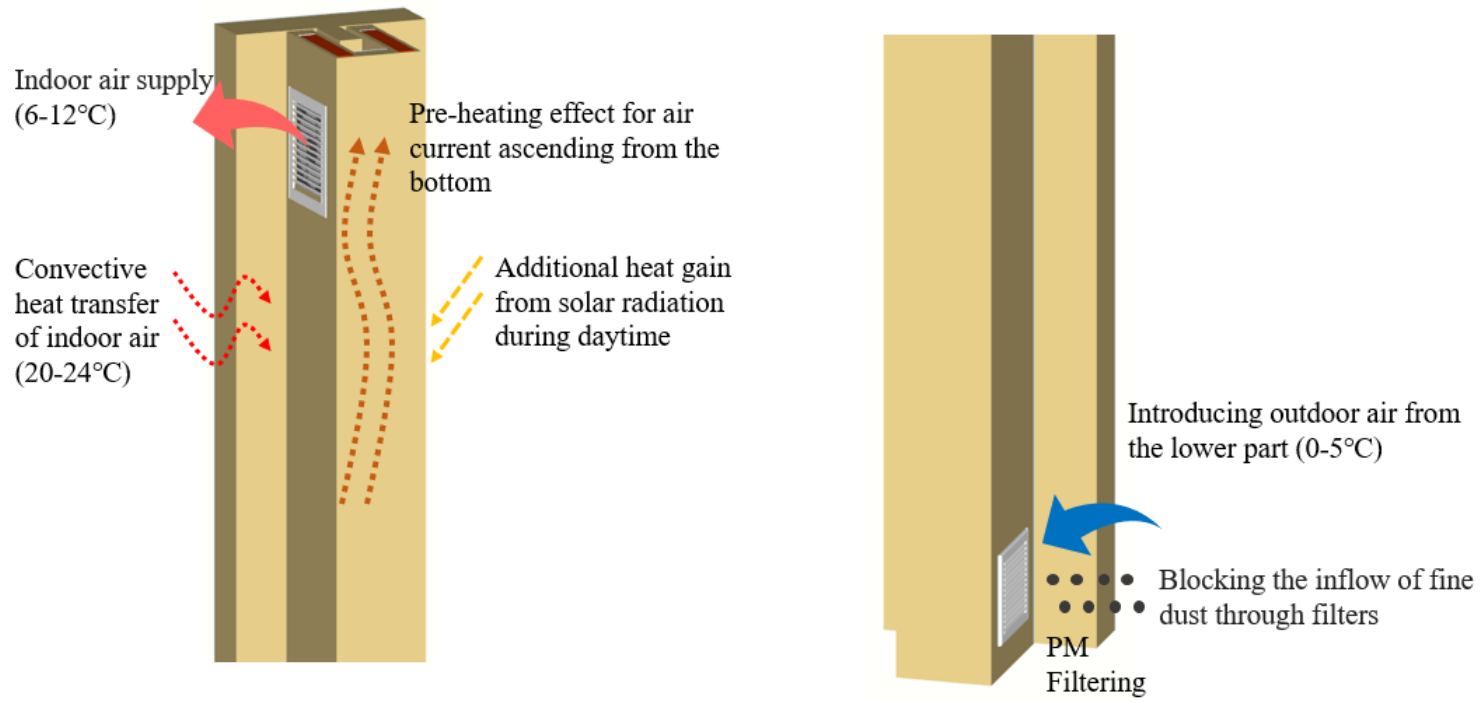

Figure 6. Operational principle of the proposed ventilation system (winter).

\subsubsection{Design Process}

Figure 7 shows the design process of the proposed system. In the typical winter climate of Korea, there is a large difference between outdoor and indoor temperatures, and heating energy consumption increases dramatically. In addition, during winter and spring, the outdoor PM concentration was relatively high. Accordingly, because the proposed ventilation system was expected to be especially useful in winter, its performance-based design was performed under winter climate conditions.

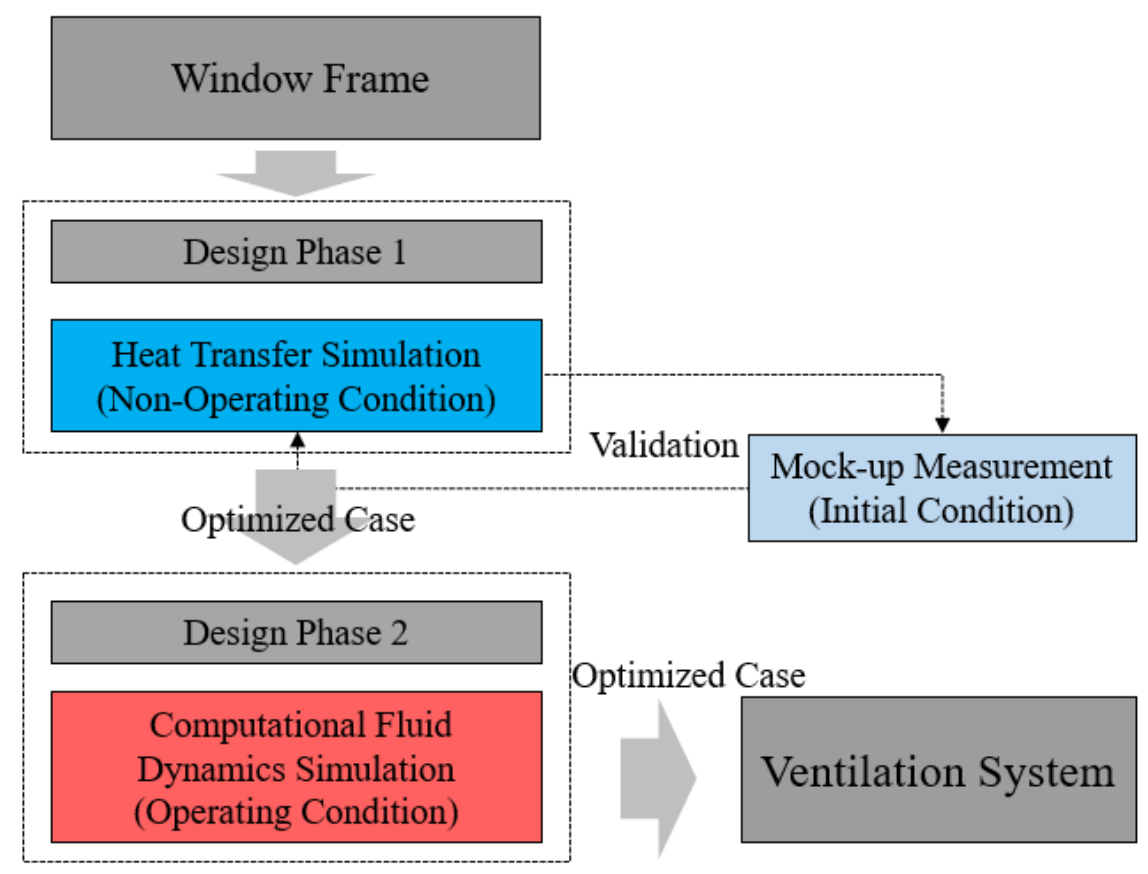

Figure 7. Design process of the proposed ventilation system.

First, referring to a condensation prevention standard, the thermal performance was examined through a heat transfer simulation. For any simulation-based model design, it is necessary to ensure the reliability of the values. For this reason, a window frame without a ventilation function was installed in the existing window of the apartment unit and measurements were made. The measurements were compared with simulation results. Candidate cases were then selected according to the shape 
modification of the window frame and the application of insulation in each location, and the simulation was carried out. After determining whether the cases caused condensation, an optimal case was selected by considering low-temperature outdoor air inflow into a cavity.

Subsequently, the optimized design of the internal supply temperature and amount of ventilation was performed in terms of the operational conditions. As solid and fluid analyses must be examined concurrently, the numerical conjugate heat transfer equation of the CFD (Computational Fluid Dynamics) simulation was applied. A curve was derived through the system flow rate and $\Delta \mathrm{P}$ (pressure drop) in the ventilation system. Then, based on the points of contact with a fan curve, actual flow rates were calculated according to each fan speed, and the design flow rate reflecting $\Delta \mathrm{T}$ (pre-heating effect) was ultimately obtained.

\subsubsection{Heat Transfer Simulation}

A heat transfer simulation was conducted to identify vulnerable system parts to heat loss and examine the location of shape modification and insulation material enhancement to prevent condensation. TRISCO 11.0 was used as a simulation program with the purpose of examining insulation and condensation based on the 3D heat transfer analysis of construction materials. For the boundary condition, PVC, which had a thermal conductivity of $0.17 \mathrm{~W} / \mathrm{m} \times \mathrm{K}$ and a low-emissivity insulation of $0.025 \mathrm{~W} / \mathrm{m} \times \mathrm{K}$, was used.

The reliability of the values had to be ensured to perform an analysis based on simulation data in the study. In this regard, the window frame in the initial shape was applied to the existing window of the actual residential area for measurement. The data were analyzed based on the outdoor and indoor temperatures corresponding to the steady-state condition.

Figure $8 \mathrm{a}$ indicates measurement points for the simulation and practical measurements. The outdoor temperature was set as $2{ }^{\circ} \mathrm{C}$ and the indoor temperature as $24^{\circ} \mathrm{C}$. Additionally, the surface temperature at three points was measured. The first point was located at the inner area, the second point at the inner side of the inner window profile, and the third point was located at the external side of the inner window profile. Figure $8 \mathrm{~b}$ shows temperatures at each point based on measurement and simulation values. Differences of 0.4 and $0.7^{\circ} \mathrm{C}$ were found at the second and fourth points, respectively. However, as can be seen in Table 1, the values were confirmed to be appropriate for the execution of the simulation because the error rate was insignificant.

Five cases were examined to estimate the status of condensation. The indoor temperature was set as $25^{\circ} \mathrm{C}$, outdoor temperature was $-15^{\circ} \mathrm{C}$, and relative humidity was $50 \%$ based on the domestic design standard for the prevention of condensation at windows. The minimum temperature at the surface of the indoor areas was compared with the dew point to determine the status of condensation.

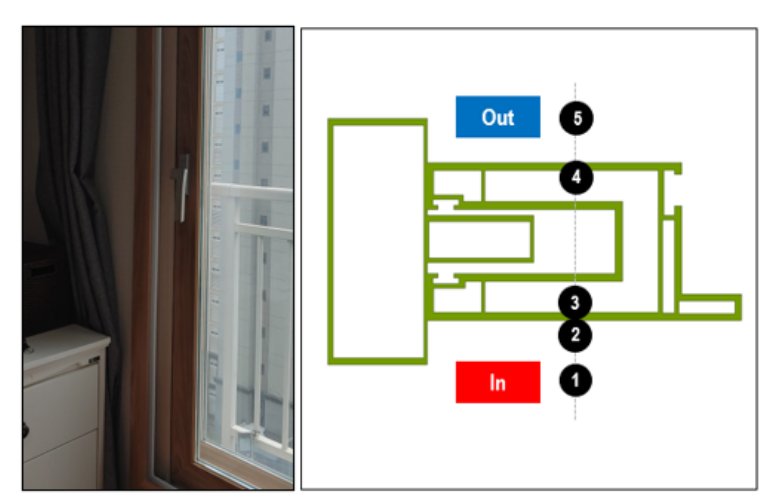

(a)

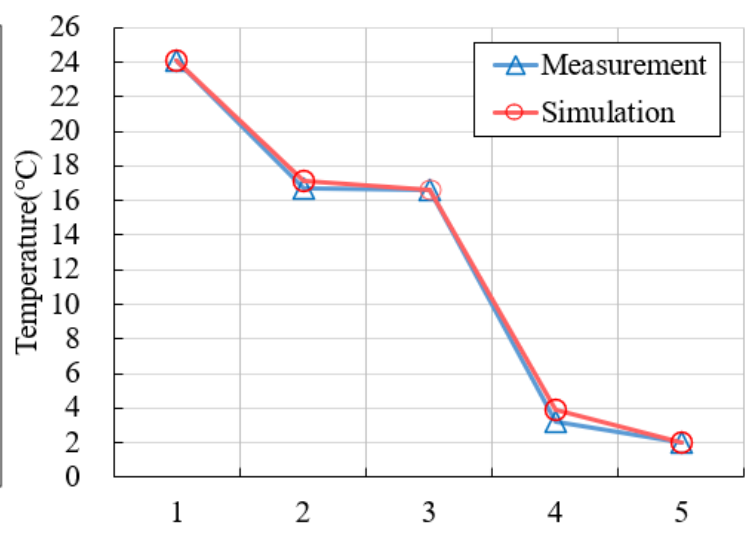

(b)

Figure 8. Comparison of measurement and simulation. (a) Measurement points and (b) surface temperature according to points. 
Table 1. Error rate between the measurement and simulation results.

\begin{tabular}{cccccc}
\hline Point & $\mathbf{1}$ (Indoor) & $\mathbf{2}$ & $\mathbf{3}$ & $\mathbf{4}$ & $\mathbf{5}$ (Outdoor) \\
\hline Measurement $\left({ }^{\circ} \mathrm{C}\right)$ & 24 & 16.7 & 16.6 & 3.2 & 2 \\
Simulation $\left({ }^{\circ} \mathrm{C}\right)$ & 24 & 17.1 & 16.6 & 3.9 & 2 \\
Error rate $(\%)$ & - & 0.02 & 0 & 0.18 & - \\
\hline
\end{tabular}

Figure 9a shows five cases of simulations from the case of the initial shape of the window frame applied to the case of insulation materials applied to the external cavity in the window frame. We assumed that the insulation materials were so closely applied as to leave no gap behind. The analysis domain excluded the air supply outlet at the upper part of the interior side and the outdoor air intake at the lower part of the exterior side. Figure $9 \mathrm{~b}$ shows the comparison of the surface temperature according to points, which was calculated based on each case. The first point refers to the indoor temperature, the second point to the surface temperature at the indoor area, the third and fourth points to the surface temperature at the cavity used as an air path during ventilation, and the fifth point to the outdoor temperature.

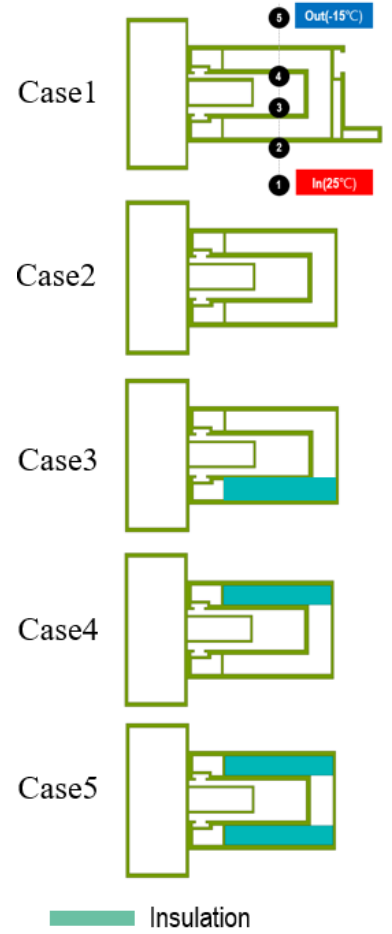

(a)

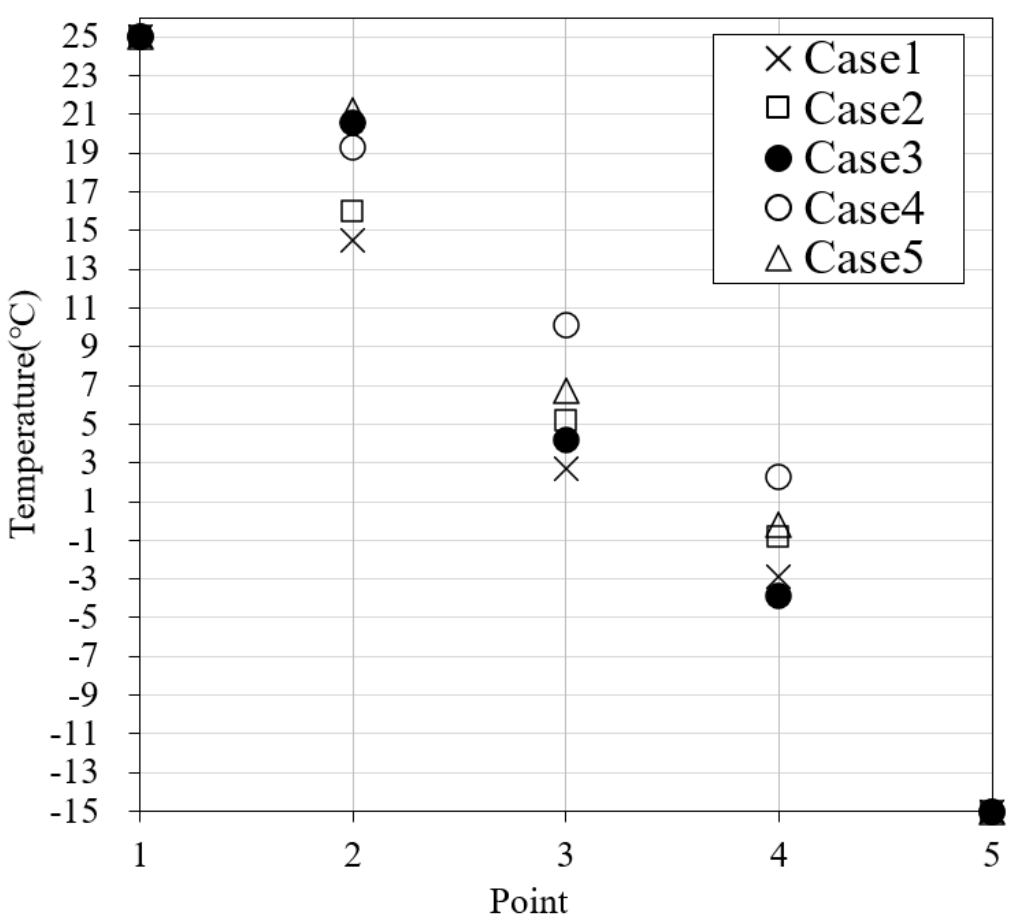

(b)

Figure 9. Comparison of five cases. (a) Shapes by case. (b) Surface temperature according to points.

In Case 1, the window frame in the initial shape was used. The wing part on the right side was vulnerable to heat loss, and this part led to a decrease in the surface temperature at the indoor area to $6.3^{\circ} \mathrm{C}$ and a high probability of condensation. In Case 2, the wing part on the right side of the window frame was removed without the application of insulation materials. The indoor surface temperature and air path temperature in Case 2 were slightly higher than those in Case 1. However, a risk of condensation was observed in some parts because the minimum temperature at the indoor surface was below the dew point temperature. In Case 3, insulation materials were applied to the inner window frame in the indoor areas. The surface temperature at the indoor area, which was represented by the second point, significantly increased. However, a risk of condensation was still observed given that the minimum surface temperature was $13.3^{\circ} \mathrm{C}$ at the part connected to the window frame. In Case 
4, insulation materials were applied to the inner window frame in the outdoor area. The insulation performance in Case 4 was the best compared to those in other cases. A risk of condensation was not observed in any of the parts with the surface temperature of an indoor area of $14.4^{\circ} \mathrm{C}$. The temperature of the cavity used as an air path was also high. In Case 5, insulation materials were applied to the inner and outer parts of the window frame. The indoor surface temperature was the highest and showed no risk of condensation. However, the temperature of the air path was not as high as that of Case 4 . This was because the application of insulation materials to the inner part of the window frame reduced the heat transfer rate from indoors to the air path.

Table 2 comprehensively presents the minimum indoor surface temperatures, dew point temperatures, and condensation status of each case. Cases 4 and 5 showed no risk of surface condensation. However, the conditions assumed that no ventilation system was in operation. Ventilation was expected to bring low-temperature outdoor air into the air path during winter and to lower the indoor surface temperature. Accordingly, the indoor surface temperatures were compared under the assumption that the air path was filled with low-temperature air. Figure 10 shows the simulation result of surface temperature in the indoor area under the assumption that the temperature of the air path was set at -15 to $0{ }^{\circ} \mathrm{C}$ in Cases 4 and 5 . In Case 4 , when the temperature of the air path was $-10^{\circ} \mathrm{C}$ and below, the indoor surface temperature became very low. On the other hand, in Case 5, when the temperature of the air path was $-15^{\circ} \mathrm{C}$, the indoor surface temperature was $17^{\circ} \mathrm{C}$, which demonstrated that the insulation performance was stably ensured. For this reason, Case 5 was chosen as the optimal case.

Table 2. Minimum surface temperature and condensation status.

\begin{tabular}{ccccccccc}
\hline Point & $\mathbf{1}$ & $\mathbf{2}$ & $\mathbf{3}$ & $\mathbf{4}$ & $\mathbf{5}$ & $\begin{array}{c}\text { Min. Surface } \\
\text { Temperature }\end{array}$ & $\begin{array}{c}\text { Dew } \\
\text { Point }\end{array}$ & $\begin{array}{c}\text { Condensation } \\
\text { Status }\end{array}$ \\
\hline Case 1 & 25 & 14.5 & 2.7 & -2.9 & -15 & 6.3 & & Yes \\
Case 2 & 25 & 16 & 5.2 & -0.8 & -15 & 13.2 & & Yes \\
Case 3 & 25 & 20.6 & 4.2 & -3.9 & -15 & 13.3 & 13.9 & Yes \\
Case 4 & 25 & 19.3 & 10.1 & 2.3 & -15 & 14.4 & & No \\
Case 5 & 25 & 21.2 & 6.7 & -0.2 & -15 & 14 & & No \\
\hline
\end{tabular}

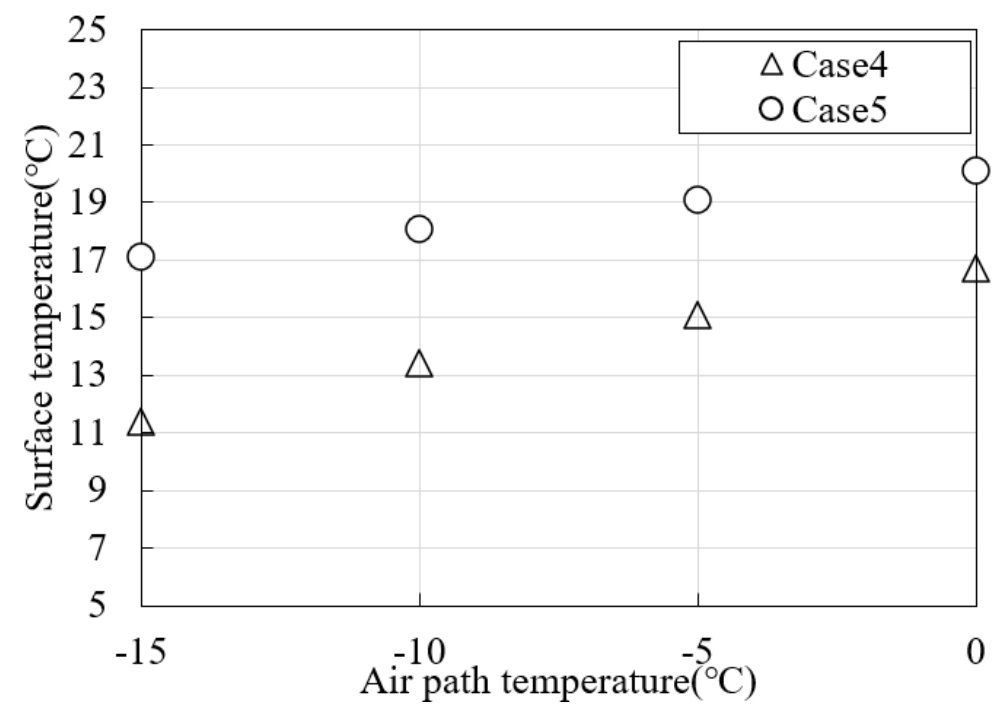

Figure 10. Indoor surface temperature according to the air temperatures in the air paths.

\subsubsection{CFD Simulation}

As described above, the optimized case under non-operating conditions was derived through a heat transfer simulation. Then, an optimal flow rate was designed by performing a heat flow CFD 
simulation based on the case. STAR CCM+ was used for the CFD program. A steady state analysis was performed with the boundary conditions of $20^{\circ} \mathrm{C}$ on the indoor side and $0{ }^{\circ} \mathrm{C}$ on the outdoor side. Two indoor air supply outlets and two outdoor air inlets were adopted for the modeling. The number of indoor air supply points was adjustable according to the necessary flow rates. This system assumed a combination of the air flow through the air path and the heat transfer of the PVC and insulation. Accordingly, a numerical equation (Equation (1)) was used, which enables a conjugate heat transfer analysis of the fluid and solid.

\section{Solid-Fluid Conjugate Heat Transfer}

$$
\mathrm{T}_{\text {solid|surface }}=\mathrm{T}_{\text {fluid|surface }} \mathrm{q}_{\text {solid|surface }}=\mathrm{q}_{\text {fluid|surface }}-\left.\mathrm{K}_{\frac{\partial T \text { solid }}{\partial n}}\right|_{\text {surface }}=\mathrm{h}_{\mathrm{f}}\left(\mathrm{T}_{\text {surface }}-\mathrm{T}_{\text {ref }}\right)+\mathrm{q}_{\text {rad }}+\mathrm{q}_{\mathrm{c}}+\cdots
$$

where $n$ is the surface outward normal; $K_{s}$ is the solid conductivity; $h_{f}$ is the fluid heat transfer coefficient; $T_{r e f}$ is the characteristic fluid temperature (for example, the domain means or near wall cell temperature); and $q_{r a d}$ and $q_{c}$ correspond to the net radiative heat flux and added heat flux due to phase change, respectively.

First, a curve between the pressure drop and flow rate in the air path of the ventilation mode was derived. Then, operating points were derived through the points of contact between the curve and fan performance curves, and actual flow rates were estimated. Finally, optimal design flow rates were selected by examining the pre-heating effect and actual flow rates for six fan speeds.

Table 3 compares the results for the six fan speeds. The comparison results include the indoor air supply velocity, actual air flow, indoor surface temperature, and air change rate (for a small room with a volume of $25 \mathrm{~m}^{3}$ ).

Table 3. Comparison of the results according to cases.

\begin{tabular}{cccccc}
\hline Cases & $\begin{array}{c}\text { Fan Speed } \\
(\mathbf{r p m})\end{array}$ & $\begin{array}{c}\text { Supply Air } \\
\text { Velocity }(\mathbf{m} / \mathbf{s})\end{array}$ & $\begin{array}{c}\text { Supply Air } \\
\text { Flow }(\mathbf{C M H})\end{array}$ & $\begin{array}{c}\text { Average Surface } \\
\text { Temperature }\left({ }^{\circ} \mathbf{C}\right)\end{array}$ & $\begin{array}{c}\text { Air Change } \\
\text { Rate }(\mathbf{A C H})\end{array}$ \\
\hline 1 & 5500 & 0.62 & 2.3 & 16.5 & 0.09 \\
2 & 10,000 & 1.47 & 6.3 & 15.8 & 0.25 \\
3 & 13,000 & 2.62 & 10.7 & 15.5 & 0.43 \\
4 & 15,000 & 3.02 & 12.5 & 15.4 & 0.5 \\
5 & 18,000 & 3.91 & 15.9 & 15.3 & 0.64 \\
6 & 19,000 & 5.05 & 21.5 & 15.2 & 0.86 \\
\hline
\end{tabular}

The higher the fan speed, the indoor air supply velocity, and the air flow tended to increase. However, the indoor surface temperature decreased slightly. This may be because a substantial indoor heat loss occurred as the air velocity increased and the temperature was lowered inside the air path. Based on the actual flow rates of each case, the air change rate was calculated to range from 0.09 to 0.86 air changes per hour. The target air change rate of the ventilation system was 0.5 air changes per hour. Thus, when the actual air volume and the air change rate per volume in the ventilation system were considered, Cases 4 to 6 were determined to be appropriate.

Figure 11 shows a graph illustrating the relationship between the actual air volume and pre-heating temperature at each fan speed. Here, the pre-heating temperature was estimated based on the supply temperature. The actual air volume was inversely proportional to the pre-heating effect. In other words, the larger the actual air volume, the smaller the pre-heating effect. This is because the heat transfer rate through convection is reduced at an increasing air supply velocity. Consequently, if both the fan speed and the actual air volume increase, the indoor air change rate also increases, which can improve indoor air quality. On the other hand, as the indoor air supply temperature decreases, occupants' thermal comfort declines, and the cost of heating ultimately increases. Additional problems may include the power consumption of the fan motor and noises. Accordingly, an optimal balancing point between the actual air volume and pre-heating temperature is essential. Among Cases 4 to 6, 
which satisfy the amount of ventilation required by the target application space, this study selected Case 4 as the optimal case because it produced the largest pre-heating effect.

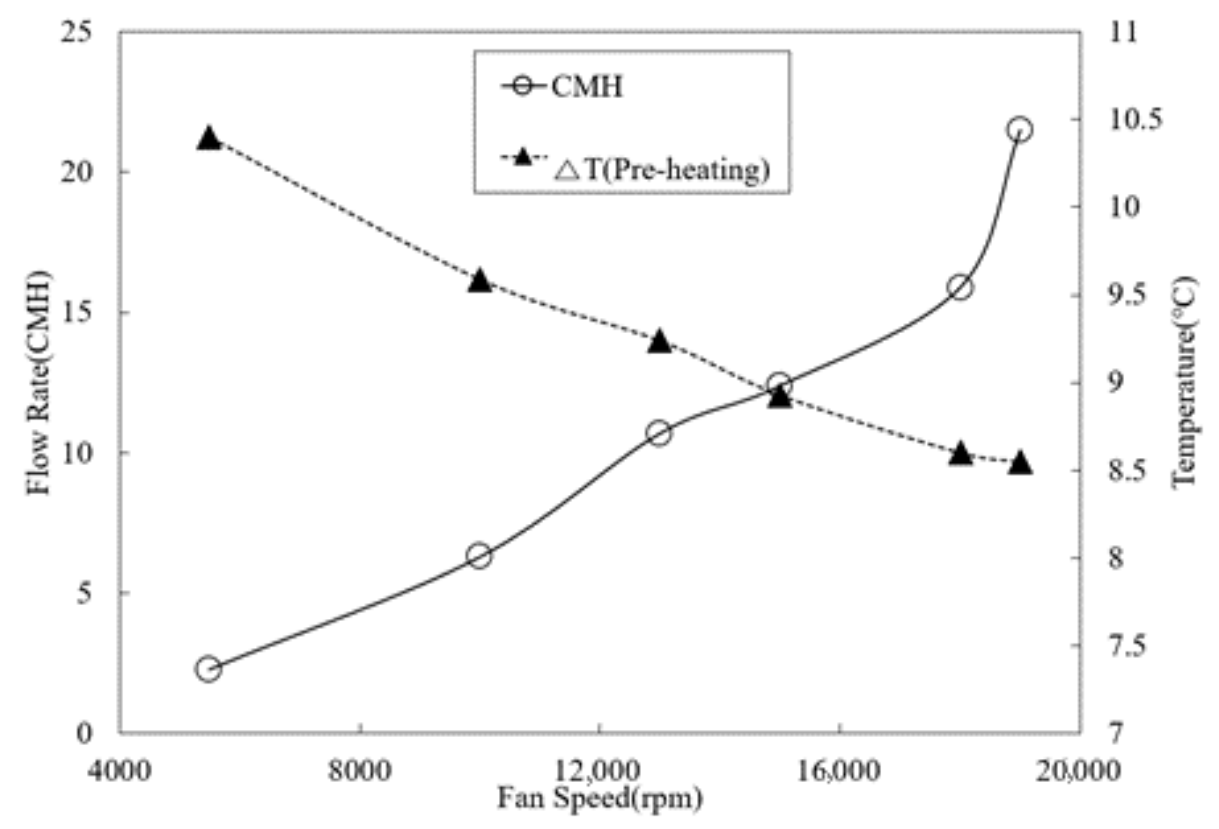

Figure 11. Relationship between the air volume and pre-heating temperature.

Figure 12a shows the analytic results of Case 4 along with the temperature distribution from the center part to the indoor air supply point in the ventilation mode. As a sufficient amount of ventilation was ensured with only a single opening part, only the upper part was set open with the lower part closed.

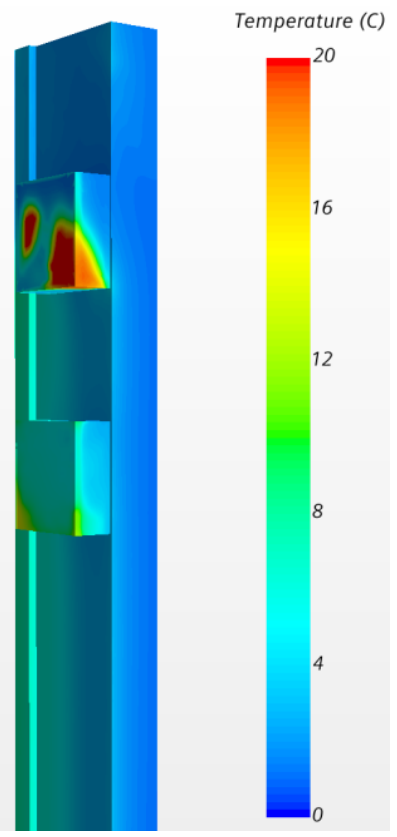

(a)

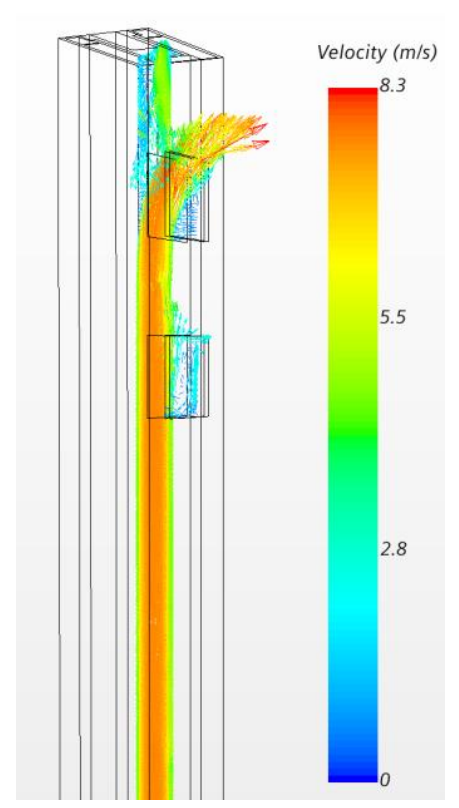

(b)

Figure 12. Temperature and velocity of the ventilation system. (a) Temperature distribution of the air path; (b) velocity magnitude of the air path. 
The upper air supply part had an average temperature of $8.9^{\circ} \mathrm{C}$. Because the air inflow condition was $0{ }^{\circ} \mathrm{C}$, the pre-heating effect of the indoor air supply was $8.9^{\circ} \mathrm{C}$. The heat exchange efficiency of the proposed ventilation system was lower than that of general ventilation systems based on heat recovery. However, this proposed system can be regarded as a substitute ventilation system from the perspective of residents considering the problems of general ventilation systems, such as an increase in the price owing to the application of heat exchange elements and the occupied area, the occurrence of condensation in the indoor area, and the difficulty of maintenance.

Figure $12 \mathrm{~b}$ shows the velocity magnitude at the air path. The maximum velocity was $8.3 \mathrm{~m} / \mathrm{s}$ near the indoor air supply outlet, and the average indoor air supply velocity was $3.02 \mathrm{~m} / \mathrm{s}$.

\subsection{Results and Discussion}

A household unit in the existing apartment in which residents lived was selected as the target area for this study, and the indoor air quality of each space in the unit was measured for data analysis. The concentration of $\mathrm{CO}_{2}$ in the living/kitchen areas exceeded $1000 \mathrm{ppm}$ when four people stayed in these areas. Nevertheless, this was not considered a serious threat because these areas were open with frequent access available to these areas. However, we determined that the concentration of PM should be managed during the cooking time through local ventilation using kitchen hoods. In Rooms 1 and 2, the concentration of $\mathrm{CO}_{2}$ constantly increased during the sleep time of residents. This result indicates that the exchange of air with outdoor air is urgently required.

However, the concentration of internal PM also instantly increased to a substantial level through natural ventilation owing to the concentration of external PM. Based on this result, we determined that the inflow of PM should be controlled during the exchange of indoor air with the outdoor air.

The ultimate design of the ventilation system was derived through the development of the system concept, heat transfer, and CFD simulation, as indicated above. Table 4 shows the specific details.

Table 4. Ventilation system.

\begin{tabular}{cccc}
\hline Components & Number of Units & \multicolumn{2}{c}{ Specification } \\
\hline Window Frame & $1 \mathrm{EA}$ & Materials & PVC \\
Low-e Insulation & $2 \mathrm{EA}$ & Size $(\mathrm{mm})$ & W65, D40, H1940 \\
& & Thermal Conductivity & $0.025 \mathrm{~W} / \mathrm{m} \times \mathrm{K}$ \\
& & Rated Voltage & $12 \mathrm{VDC}$ \\
Fan & 1EA & Input Current & $0.25 \mathrm{~A}(\max 0.5 \mathrm{~A})$ \\
& & Speed & $15,000 \mathrm{RPM}$ \\
& & Actual Air Volume & $12.5 \mathrm{CMH}$ \\
Particle Filter & Size (mm) & $40 \times 40 \times 28$ \\
Vent Grill & Types & Matters \\
& 2EA & Grades & H11 (EN1822) \\
\end{tabular}

Figure 13a,b display the upper and lower parts of the designed 3D ventilation system, respectively. At the upper part of this system, a fan was applied to force the outdoor fresh air to flow into the indoor areas. The upper part of this fan was finished with a vent grill. Low-emission insulation with a thermal conductivity of $0.025 \mathrm{~W} / \mathrm{m} \times \mathrm{K}$ was applied at the internal sides of the "U"-shaped area to perform insulation and prevent condensation. At the lower part, a hole was generated to allow the external fresh air to flow into the internal area. A filter net was applied to the hole to prevent PM, and the filter grade was established as H11 (EN1822) consistent with the grade of high-efficiency particulate air (HEPA) filter. This filter was used to filter the PM, and the resident was allowed to easily replace it with another one when it could no longer be used. 


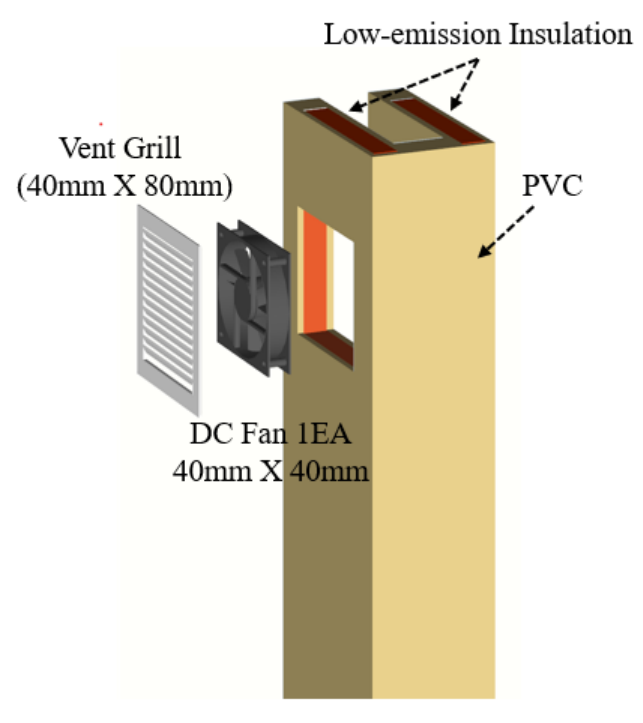

(a)

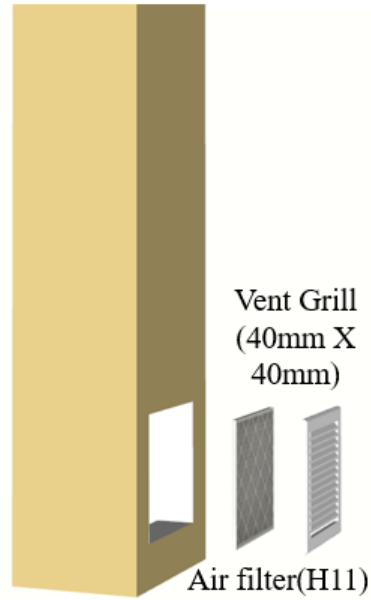

(b)

Figure 13. Ventilation system component temperature and velocity of the ventilation system. (a) Upper components; (b) lower components.

\section{Conclusions}

This study proposed a new ventilation system that was appropriate to the room of an apartment in which the improvement of indoor air quality was analyzed based on the aforementioned experimental results. This system can be easily applied to existing houses without ventilation systems and utilizes a window cavity, which is created between a new frame and an existing one, as an air path for ventilation. Specifically, insulation materials were used in the cavity of the window frame to prevent condensation. A filter net was also applied on the external sides of the lower parts to control the inflow of PM. The locations of insulation materials were examined based on the heat transfer simulation, and the balance between the actual flow rate and pre-heating temperature was optimized through a CFD simulation analysis. When the ultimate design flow rate of $12.5 \mathrm{CMH}$ was assumed, the indoor heat transfer alone could result in a pre-heating effect of $8.9^{\circ} \mathrm{C}$.

The application of the ventilation system designed in this study sufficiently enhances the indoor air quality in the small room targeted in this study. Moreover, it is also expected to decrease the concentration of $\mathrm{CO}_{2}$, which rapidly increases during the sleep time of residents.

Field measurements are essential to substantially verify this developed system. Further studies will be conducted to generate a practical mockup type of the developed system and apply it to the actual space for verification processes. In addition, the possibility of implementing this system as a practical product will be examined through a comprehensive analysis based on the status of the satisfactory amount of ventilation, verification of supply temperature, and the effects of PM prevention.

Author Contributions: Conceptualization, S.P. and J.L.; methodology, J.L.; software, J.L.; validation, J.L.; formal analysis, J.L.; investigation, T.K.; resources, J.L.; data curation, J.L.; writing-original draft preparation, J.L.; writing-review and editing, J.L.; visualization, J.L.; supervision, T.K.; project administration, T.K.; funding acquisition, T.K. All authors have read and agreed to the published version of the manuscript.

Funding: This work was supported by a National Research Foundation of Korea (NRF) grant funded by the Korean government (MSIT, MOE) and (No. 2019M3E7A1113095). ※ MSIT: Ministry of Science and ICT, MOE: Ministry of Education.

Conflicts of Interest: The authors declare that they have no known competing financial interests or personal relationships that could have appeared to influence the work reported in this paper. 


\section{References}

1. Derbez, M.; Berthineau, B.; Cochet, V.; Lethrosne, M.; Pignon, C.; Ribéron, J.; Kirchner, S. Indoor Air Quality and Comfort in Seven Newly Built, Energy-Efficient Houses in France. Build. Environ. 2014, 72, 173-187. [CrossRef]

2. Du, L.; Prasauskas, T.; Leivo, V.M.; Turunen, M.; Pekkonen, M.; Kiviste, M.; Aaltonen, A.; Martuzevicius, D.; Haverinen-Shaughnessy, U. Assessment of Indoor Environmental Quality in Existing Multi-Family Buildings in North-East Europe. Environ. Int. 2015, 79, 74-84. [CrossRef] [PubMed]

3. Liu, J.; Dai, X.; Li, X.; Jia, S.; Pei, J.; Sun, Y.; Lai, D.; Shen, X.; Sun, H.; Yin, H.; et al. Indoor Air Quality and occupants' Ventilation Habits in China: Seasonal Measurement and Long-Term Monitoring. Build. Environ. 2018, 142, 119-129. [CrossRef]

4. Dai, X.; Liu, J.; Li, X.; Zhao, L. Long-Term Monitoring of Indoor $\mathrm{CO}_{2}$ and $\mathrm{PM}_{2.5}$ in Chinese Homes: Concentrations and Their Relationships with Outdoor Environments. Build. Environ. 2018, 144, $238-247$. [CrossRef]

5. Leivo, V.M.; Turunen, M.; Aaltonen, A.; Kiviste, M.; Du, L.; Haverinen-Shaughnessy, U. Impacts of Energy Retrofits on Ventilation Rates, $\mathrm{CO}_{2}$-Levels and Occupants' Satisfaction With Indoor Air Quality. Energy Procedia 2016, 96, 260-265. [CrossRef]

6. Sharpe, T.; Farren, P.; Howieson, S.; Tuohy, P.; McQuillan, J. Occupant Interactions and Effectiveness of Natural Ventilation Strategies in Contemporary New Housing in Scotland, UK. Int. J. Environ. Res. Public Health 2015, 12, 8480-8497. [CrossRef]

7. Bekö, G.; Lund, T.; Nors, F.; Toftum, J.; Clausen, G. Ventilation Rates in the Bedrooms of 500 Danish Children. Build. Environ. 2010, 45, 2289-2295. [CrossRef]

8. Canha, N.; Mandin, C.; Ramalho, O.; Wyart, G.; Ribéron, J.; Dassonville, C.; Hänninen, O.; Almeida, S.; Derbez, M. Assessment of Ventilation and Indoor Air Pollutants in Nursery and Elementary Schools in France. Indoor Air 2015, 26, 350-365. [CrossRef]

9. Canha, N.; Alves, A.C.; Marta, C.S.; Lage, J.; Belo, J.; Faria, T.; Verde, S.C.; Viegas, C.; Alves, C.A.; Almeida, S.M. Compliance of Indoor Air Quality During Sleep With Legislation and Guidelines - A Case Study of Lisbon Dwellings. Environ. Pollut. 2020, 264, 114619. [CrossRef]

10. Strøm-Tejsen, P.; Zukowska-Tejsen, D.; Wargocki, P.; Wyon, D.P. The Effects of Bedroom Air Quality on Sleep and next-day Performance. Indoor Air 2015, 26, 679-686. [CrossRef]

11. Zhang, N.; Cao, B.; Zhu, Y. Indoor Environment and Sleep Quality: A Research Based on Online Survey and Field Study. Build. Environ. 2018, 137, 198-207. [CrossRef]

12. Canha, N.; Lage, J.; Candeias, S.; Alves, C.; Almeida, S.M. Indoor Air Quality during Sleep under Different Ventilation Patterns. Atmospheric Pollut. Res. 2017, 8, 1132-1142. [CrossRef]

13. Accinelli, R.A.; Llanos, O.; Lopez, L.; Pino, M.I.; Bravo, Y.A.; Salinas, V.; Lazo-Porras, M.; Noda, J.R.; Sánchez-Sierra, M.; Zárate, L.; et al. Adherence to Reduced-Polluting Biomass Fuel Stoves Improves Respiratory and Sleep Symptoms in Children. BMC Pediatr. 2014, 14, 12. [CrossRef] [PubMed]

14. Ai, Z.; Mak, C.M.; Niu, J.; Li, Z. The Assessment of the Performance of Balconies Using Computational Fluid Dynamics. Build. Serv. Eng. Res. Technol. 2011, 32, 229-243. [CrossRef]

15. Chand, I.; Bhargava, P.; Krishak, N. Effect of Balconies on Ventilation Inducing Aeromotive Force on Low-Rise Buildings. Build. Environ. 1998, 33, 385-396. [CrossRef]

16. Maier, T.; Krzaczek, M.; Tejchman, J. Comparison of Physical Performances of the Ventilation Systems in Low-Energy Residential Houses. Energy Build. 2009, 41, 337-353. [CrossRef]

17. Choi, Y.; Song, D. How to Quantify Natural Ventilation Rate of Single-Sided Ventilation With Trickle Ventilator? Build. Environ. 2020, 181, 107119. [CrossRef]

18. Chen, C.; Zhao, B. Review of Relationship between Indoor and Outdoor Particles: I/O Ratio, Infiltration Factor and Penetration Factor. Atmospheric Environ. 2011, 45, 275-288. [CrossRef]

19. Kim, J.-H.; Kim, H.-J.; Yoo, S.-H. Public Value of Enforcing the $\mathrm{PM}_{2.5}$ Concentration Reduction Policy in South Korean Urban Areas. Sustainability 2018, 10, 1144. [CrossRef]

20. Gao, J.; Woodward, A.; Vardoulakis, S.; Kovats, R.S.; Wilkinson, P.; Li, L.; Xu, L.; Li, J.; Yang, J.; Cao, L.; et al. Haze, Public Health and Mitigation Measures in China: A Review of the Current Evidence for Further Policy Response. Sci. Total Environ. 2017, 578, 148-157. [CrossRef] 
21. Carlos, J.S.; Corvacho, H.; Silva, P.D.; Castro-Gomes, J. Real Climate Experimental Study of Two Double Window Systems With Preheating of Ventilation Air. Energy Build. 2010, 42, 928-934. [CrossRef]

22. Carlos, J.S. Optimizing the Ventilated Double Window for Solar Collection. Sol. Energy 2017, 150, 454-462. [CrossRef]

23. De Gracia, A.; Castell, A.; Navarro, L.; Oró, E.; Cabeza, L.F. Numerical Modelling of Ventilated Facades: A Review. Renew. Sustain. Energy Rev. 2013, 22, 539-549. [CrossRef]

24. Carlos, J.S.; Corvacho, H.; Silva, P.D.; Castro-Gomes, J.; Sedira, N. Modelling and Simulation of a Ventilated Double Window. Appl. Therm. Eng. 2011, 31, 93-102. [CrossRef]

25. Carlos, J.S.; Corvacho, H.; Silva, P.D.; Castro-Gomes, J.; Sedira, N. Heat Recovery Versus Solar Collection in a Ventilated Double Window. Appl. Therm. Eng. 2012, 37, 258-266. [CrossRef]

26. Liu, M.; Heiselberg, P.K.; Larsen, O.K.; Mortensen, L.; Rose, J. Investigation of Different Configurations of a Ventilated Window to Optimize Both Energy Efficiency and Thermal Comfort. Energy Procedia 2017, 132, 478-483. [CrossRef]

27. Appelfeld, D.; Svendsen, S. Experimental Analysis of Energy Performance F a Ventilated Window for Heat Recovery under Controlled Conditions. Energy Build. 2011, 43, 3200-3207. [CrossRef]

28. Dugué, A.; Raji, S.; Bonnamy, P.; Bruneau, D. E2VENT: An Energy Efficient Ventilated Façade Retrofitting System. Presentation of the Embedded LHTES System. Procedia Environ. Sci. 2017, 38, 121-129. [CrossRef]

29. Martinez, A.; Urra, I.; Hernandez, J.; Diallo, T.; Zhao, X. Development of a Smart Modular Heat Recovery Unit Adaptable into a Ventilated Façade. Procedia Environ. Sci. 2017, 38, 94-101. [CrossRef]

30. Coydon, F.; Herkel, S.; Kuber, T.; Pfafferott, J.; Himmelsbach, S. Energy Performance of façade Integrated Decentralized Ventilation Systems. Energy Build. 2015, 107, 172-180. [CrossRef]

31. Dermentzis, G.; Ochs, F.; Siegele, D.; Feist, W. Renovation With an Innovative Compact Heating and Ventilation System Integrated into the façade-An in-Situ Monitoring Case Study. Energy Build. 2018, 165, 451-463. [CrossRef]

32. Bielek, B.; Szabó, D.; Lavrinčík, M. Transparent Elemental Facade with an Integrated Ventilation Unit for a High-Rise Building-Development and Experimental Verification. Slovak J. Civ. Eng. 2018, 26, 66-77. [CrossRef]

33. Zhang, N.; Jin, W.; He, J. Experimental Study on the Influence of Ventilated Window on Indoor Air Quality and Energy Consumption. Procedia Eng. 2016, 146, 296-302. [CrossRef] 